\title{
Ujaran Maaf dalam Bahasa Jepang dan Bahasa Bali
}

\author{
Ni Kadek Nova Suardani Rahayu \\ Prodi Sastra Jepang, Fakultas Ilmu Budaya, Unud \\ [novasuardani@gmail.com]
}

\begin{abstract}
This study is focused to the speech of apology found in Japanese novel entitled Houkago ni Shisha wa Modoru by Akiyoshi Rikako and Balinese novel entitled Tresnane Lebur Ajur Satonden Kembang by Djelantik Santha. The aims of this study are to know the functions and factors that affect and also the comparison of apology speech between Japanese and Balinese languages. Theori use in this study is theory of level politeness factors proposed by Mizutani and Mizutani (1991) and apology proposed by Alwi (2005). Method and technique of collecting the data used in this study are observation method and descriptive analysis technique. The result of this study showed that there are twelve speechs of apology that functionate as a sense of regret and six speechs of apology as a permission request found in the Houkago ni Shisha wa Modoru novel. The factors that influence the speech of apology in Japanese are the proximity of relationship and age factors. There are fifteen speechs of apology in Japanese. Meanwhile, in Balinese novel entitled Tresnane Lebur Ajur Satonden Kembang one speech of apology who has a function of exemption from the punishment, seven speechs of apology as the sense of regret, four speechs of apology as permission request and one speech of apology as the humble act. Factors that influence the speech of apology in Balinese language are social status and age factors. In Balinese, there are six kinds of apology speech. The data that has been analyzed show that Japanese and Balinese language have two similaries and three differences.
\end{abstract}

Keywords: speech, apology, function, factor.

\begin{abstract}
Abstrak
Skripsi ini difokuskan pada ujaran maaf yang terdapat dalam novel bahasa Jepang yang berjudul Houkago ni Shisha wa Modoru karya Akiyoshi Rikako dan novel bahasa Bali yang berjudul Tresnane Lebur Ajur Satonden Kembang karya Djelantik Santha. Penelitian ini bertujuan untuk mengetahui fungsi dan faktor yang memengaruhi ujaran maaf dalam bahasa Jepang dan bahasa Bali. Selain itu, penelitian ini juga melihat perbandingan ujaran maaf dalam bahasa Jepang dan bahasa Bali.Teori yang digunakan dalam skripsi ini adalah teori Faktor Tingkat Kesantunan dari Mizutani dan Mizutani (1991) dan Maaf menurut Alwi (2005). Metode dan teknik data yang digunakan dalam penelitian ini adalah metode simak dan teknik deskriptif analisis.Hasil analisis menunjukkan bahwa pada novel Houkago ni Shisha wa Modoru ditemukan dua belas buah ujaran maaf yang berfungsi menunjukkan rasa penyesalan dan enam buah ujaran maaf yang berfungsi meminta izin. Faktor yang memengaruhi ujaran maaf dalam bahasa Jepang adalah faktor kedekatan hubungan dan usia. Pada ujaran maaf bahasa Jepang ditemukan lima belas jenis ujaran maaf. Sedangkan pada novel Tresnane Lebur Ajur Satonden Kembang ditemukan satu buah ujaran maaf yang berfungsi untuk pembebasan dari hukuman, tujuh buah ujaran maaf yang berfungsi menunjukkan rasa penyesalan, empat buah ujaran maaf yang berfungsi meminta izin dan satu buah ujaran maaf yang berfungsi merendahkan diri. Faktor yang memengaruhi ujaran maaf dalam bahasa Bali adalah
\end{abstract}


faktor status sosial dan usia. Pada ujaran maaf bahasa Bali ditemukan enam jenis ujaran maaf. Dari data yang telah dianalisis menunjukkan bahwa pada ujaran maaf bahasa Jepang dan bahasa Bali memiliki duah buah persamaan dan tiga buah perbedaan.

Kata kunci: Ujaran, maaf, fungsi, faktor.

\section{Latar Belakang}

Bahasa merupakan alat komunikasi yang digunakan untuk menyampaikan ide, gagasan, pikiran, maupun perasaan kepada orang lain. Penyampaian bahasa yang tidak dapat ditangkap baik oleh mitra tutur menyebabkan maksud dari ujaran yang ingin disampaikan tidak dapat diterima oleh mitra tutur. Cara yang dapat digunakan untuk mengetahui maksud dari ujaran penutur agar dapat ditangkap dengan baik oleh mitra tutur, yaitu melalui pragmatik.

Levinson (1983:21-24) menjelaskan pengertian pragmatik diantaranya adalah Pragmatics is the study of the relation between language and context that are basic to an account of language understanding dan Pragmatics is the study of the ability of language users to pair sentences with the contexts in which they would be appropriate. Pada dua buah pengertian tersebut menunjukkan bahwa penggunaan bahasa dan konteks ujaran. Penggunaan bahasa di sini menyangkut fungsi bahasa.

Alwasilah (2011:93) menyatakan, bahasa berfungsi sebagai lem perekat dalam menyatupadukan keluarga, masyarakat, dan bahasa dalam kegiatan sosialisasi. Fungsi terpenting dari bahasa adalah alat komunikasi dan interaksi. Jacobson dalam (Alwasilah, 2011:93) menyebutkan ujaran berfungsi sebagai alat komunikasi. Finocchiaro dalam (Alwasilah, 2011:94) menyebutkan fungsi ujaran sebagai alat komunikasi, yaitu Personal, Interpersonal, Directive, Referential, Metalinguistic, dan Imaginative. Ujaran directive merupakan jenis ujaran yang bertujuan untuk mengendalikan orang lain. Salah satu contoh ujuran directive yaitu ujaran permintaan. Seperti ujaran maaf.

Ungkapan maaf pada ujaran, tidak hanya diucapkan ketika melakukan kesalahan, namun ujaran maaf dapat memiliki fungsi yang lainnya, yaitu permohonan izin dan merendahkan diri. Bahasa Jepang dan bahasa Bali memiliki pengertian untuk fungsi ujaran maaf lebih dari satu dan fakor yang melatar belakanginya juga berbeda menurut norma yang berlaku dalam masyarakat Jepang dan Bali.

\section{Pokok Permasalahan}

Berdasarkan latar belakang tersebut, dapat dirumuskan permasalahan sebagai berikut.

a. Bagaimanakah fungsi ujaran maaf dalam bahasa Jepang dan bahasa Bali?

b. Bagaimanakah faktor yang memengaruhi ujaran maaf dalam bahasa Jepang dan bahasa Bali?

\section{Tujuan Penelitian}

Penelitian ini bertujuan untuk menambah wawasan pembaca terhadap bidang ilmu linguistik khususnya dalam bidang pragmatik dan untuk mengetahui fungsi beserta faktor yang memengaruhi ujaran maaf dalam bahasa Jepang dan Bali.

\section{Metode Penelitian}

Penelitian ini menggunakan novel berbahasa Jepang yang berjudul Houkago ni Sisha wa Modoru karya Akiyoshi Rikako (2014) dan novel berbahasa Bali yang berjudul Tresnane Lebur Ajur 
Satonden Kembang karya Djelantik Santha (2011). Pada prosedur pengumpulan data, penelitian ini menggunakan metode simak dan teknik catat. Metode simak merupakan cara memperoleh data dengan menyimak penggunaan bahasa dan Teknik catat adalah mencatat data yang telah diperoleh dalam proses menyimak. (Mahsun, 2013:92). Teknik analisis data yang digunakan adalah deskriptif. Deskriptif merupakan gambaran ciri-ciri data secara akurat sesuai dengan sifat alamiah itu sendiri (Djajasudarma, 1993:16). Setelah data dianalisis, tahap selanjutnya adalah penyajian hasil analisis data dengan menggunakan metode informal (Sudaryanto, 2015: 241).

\section{Hasil dan Pembahasan}

Pada bagian ini dijelaskan mengenai hasil analisis data mengenai fungsi ujaran maaf dalam bahasa Jepang dan Bali, dan faktor yang memengaruhi ujaran maaf dalam bahasa Jepang dan Bali.

\subsection{Fungsi dan Faktor Ujaran Maaf dalam Bahasa Jepang}

Pada novel berbahasa Jepang yang berjudul Houkago ni Shisha wa Modoru karya Akiyoshi Rikako, ditemukan data yang memiliki dua fungsi maaf yaitu maaf untuk menunjukkan rasa penyesalan dan maaf untuk meminta izin

\subsubsection{Maaf untuk Menunjukkan Rasa Penyesalan}

Maaf untuk menunjukkan rasa penyesalahan ditemukan 12 buah ujaran. Berikut contoh hasil analisis untuk ujaran maaf untuk menunjukkan rasa penyesalan

$$
\text { （1）高橋真治 ：一美夏、ちゃん? . }
$$

美夏 : やめてよ、ちゃんづけ。 キモイ」.

高橋真治：ああ、ごめん.

(放課後に死者は戻る. 2014:59)

Takahashi Shinji : ...Mika ..chan?

Mika : Yamete yo, chanduke. Kimoi.

Takahashi Shinji : Aa, gomen.

(Houkago ni Sisha wa Modoru. 2014:59)

Takahashi Shinji : ...Mika ..chan?

Mika : Hentikan memanggilku dengan chan. Menjijikkan.

Takahashi Shinji : Ah, Maaf.

Ujaran pada data (1) merupakan ujaran Takahashi Shinji dengan Mika yang terjadi ketika Mika tidak sengaja bertemu dengan Takahashi Shinji yang sedang berada di taman. Takahashi Shinji yang merasa terkejut karena ada yang memanggil namanya tiba-tiba, lalu mengatakan "...Mika ..chan". Mika yang dipanggil dengan sebutan "chan" merasa kesal, dikarenakan menurut Mika penggunaan kata "chan" dibelakang namanya adalah hal menjijikan, sehingga menyebabkan Takahashi Shinji merasa menyesal telah memanggil Mika dengan sebutan yang tidak disukainya. Penyesalan Takahashi Shinji diekspresikan dengan ujaran maaf "Gomen" yang berarti "Maaf". Takahashi Shinji dan Mika memiliki hubungan yang akrab sebagai teman satu band. Hal ini dapat dilihat dari kalimat "...Mika ..chan" dikarenakan penggunaan kata "chan" merupakan penyebutan untuk yang memiliki hubungan akrab yang digunakan di akhiran nama anak perempuan atau laki-laki sebagai pengganti "san". Kedekatan hubungan ini dikarenakan Mika dan Takahashi Shinji merupakan pelajar kelas 2 SMA yang memiliki usia sekitar 17 tahun. Usia yang 
sebaya menyebabkan mereka dapat melakukan ujaran tanpa aturan (Mizutani dan Mizutani, 1991:4).

Berdasarkan ujaran pada data (1), dapat disimpulkan bahwa ujaran "gomen" mempunyai fungsi maaf untuk menunjukkan rasa penyesalan. Faktor yang memengaruhi ujaran maaf penutur, yaitu adanya keakraban hubungan, usia yang sama dan dari anggota kelompok yang sama yaitu mereka tergabung dalam band yang sama.

\subsubsection{Maaf untuk Meminta Izin}

Maaf untuk meminta izin ditemukan 6 buah ujaran. Berikut contoh hasil analisis untuk ujaran maaf meminta izin

(2) 高橋真治

$$
\begin{gathered}
\text { ：お！悪いけど、俺、 } \\
\text { 先に行くぜ！ } \\
\text { のぶお、吉雄： . . . } \\
\text { (放課後に死者は戻る. 2014:222) }
\end{gathered}
$$

Takahashi Shinji : O ! Waruikedo. Ore,
saki ni iku ze!
Nobuo, Yoshio $\quad \therefore . . . .$.
$\quad$ (Houkago ni Sisha wa Modoru. 2014:22)

Takahashi Shinji : Oh! Maaf aku duluan ya!

Nobuo, Yoshio

Ujaran pada data (2) merupakan ujaran Takahashi Shinji, Nobuo, dan Yoshio ketika mereka sedang menuruni tangga sekolah untuk menyaksikan penyalaan api unggun di halaman sekolah. Takahashi Shinji yang tidak sabar untuk menyaksikan penyalaan api unggun memohon maaf kepada Nobuo dan Yoshio untuk lebih dulu ke lapangan, dikarenakan Nobuo dan Yoshio yang asyik mengobrol menyebabkan mereka berjalan menjadi lambat sedangkan Takahashi Shinji tidak ingin melewatkan penyalaan api unggun sebagai penanda berakhirnya festival sekolah. Ujaran maaf yang digunakan oleh Takahashi Shinji yaitu "Warui" yang berarti "Maaf". Maaf yang dituturkan oleh Takahashi Shinji menunjukkan permohonan izin untuk dapat melakukan sesuatu yang diinginkannya, yaitu meminta izin untuk lebih dulu menuju ke halaman sekolah. Ujaran Takahashi Shinji yang menggunakan akhiran "ze" pada akhiran ujarannya menunjukkan adanya kedekatan hubungan yang dimiliki oleh mereka, dikarenakan penggunaan partikel pada kalimat akhir seperti " $s a$ ", " $z e$ " dan " $z o$ " diguanakan saat melakukan ujaran yang akrab, biasanya digunakan ketika berbicara dengan teman atau anggota keluarga (Mizutani dan Mizutani, 1991:62). Hubungan yang dekat ini, dikarenakan mereka adalah teman sekelas dan memiliki usia yang sebaya yaitu sekitar 17 tahun sehingga mereka dapat melakukan ujaran tanpa aturan (Mizutani dan Mizutani, 1991:4).

Berdasarkan ujaran pada data (2), dapat disimpulkan bahwa dari ujaran "warui" memiliki fungsi maaf untuk meminta izin. Faktor yang memengaruhi ujaran maaf tersebut adalah adanya hubungan yang dekat, usia yang sama, dan mereka dari anggota kelompok yang sama sebagai teman sekelas.

\subsection{Fungsi dan Faktor Ujaran Maaf dalam Bahasa Bali}

Pada novel berbahasa Bali yang berjudul Tresnane Lebur Ajur Satonden Kembang karya Djelantik Santha, ditemukan data yang memiliki fungsi maaf untuk pembebasan dari hukuman, maaf untuk menunjukkan rasa penyesalan, maaf untuk meminta izin dan maaf untuk merendahkan diri 
5.2.1 Maaf untuk Pembebasan dari Hukuman

Maaf untuk pembebasan dari hukuman ditemukan 1 buah ujaran. Berikut contoh hasil analisis untuk ujaran maaf pembebasan dari hukuman

(3) Jero Seka :Napi ko ten wénten.Kénkénang Gung Alit lunga ten morah orahan tekén anak tua. Laguté ngelah bayu akas, Kadén nyidaang baan mragatang pedidi"

Gung Alit : Enggih mémé, ajung. Madé minakadi pekak Giyor pada makejang. Tiang saja pelih. Tiang bungeng, paling. Ten tepuk baan tiang ngalih pajalané ané melah, ané tuara lakar nyakitin keneh tiangé. pang sepalaan tiang nunas

pengampura, mawanan lagas keneh tiangé ngajak Madé Arini mriki. Sapunapi patutné salantur ipun, kanggéna ajung mangkin mikayunin sareng pekak Giyor deriki. Titiang nyerah, puput

(Tresnané Lebur Ajur Satondén Kembang. 2011:88)

Jero Sekar : Apanya tidak apa-apa. Gung Alit pergi tanpa bilang apa-apa ke orang tua. Mentangmentang dirinya kuat, dikira bisa menyelesaikan sendiri?

Gung alit : Iya ibu, ayah. Made terutama pekak Giyor semuanya. Saya memang yang salah. Saya benar-benar bingung. Saya tidak dapat mencari jalan keluar yang benar, dimana akan menyakiti perasaan saya. Agar sekalian saya memohon maaf, karena sudah berani membawa Made Arini kesini. Bagaimana seharusnya ini, terserah ayah sekarang maunya bagaimana dengan kakek
Giyor disini. Saya menyerah, selesai.

Ujaran pada data (3) merupakan ujaran Jero Sekar dan Gung Alit ketika Jero Sekar dan Gung Ngurah datang menemui Gung Alit di rumah kakek Giyor. Gung Alit yang dibutakan oleh cinta setelah Made Arini menolaknya, menyebabkan ia nekat membawa kabur Made Arini dengan pikiran ia harus mendapatkan Made Arini terlebih dahulu, setelah itu ia akan memohon maaf. Ujaran maaf Gung Alit dikarenakan tindakan dan pemikirannya tersebut yaitu "nunas pengampura" yang berarti "mohon maaf". Perbuatan Gung Alit yang menculik Made Arini di tengah jalan lalu dikawinkan secara paksa di rumah kakek Giyor disebut dengan paisaca wiwaha. Perkawinan ini digunakan oleh pria untuk menjebak wanita yang disukainya dengan merusak kehormatannya tindakan tersebut dapat diancam hukuman pidana. Perbuatan Gung Alit yang menculik Made Arini menyebabkan orang tua Gung Alit malu kepada masyarakat dikarenakan Gung Alit dari keturunan ksatria wangsa yang dihormati dan melakukan pernikahan tidak sesuai dengan adat. Selain itu, orang tua Gung Alit juga menjadi pihak yang bertanggung jawab dengan memohon maaf ke rumah keluarga Made Arini dan mencari jalan keluar akibat tindakan Gung Alit. Tindakan Gung Alit menyebabkan Made Arini tidak dapat melanjutkan sekolahnya dan terpaksa harus berpisah dengan kekasihnya. Selain itu, tindakan Gung Alit juga menyebabkan kakek Giyor ikut terlibat dalam permasalahan Gung Alit. Ujaran antara Jero Sekar dan Gung Alit menunjukkan, meskipun mereka memiliki hubungan keluarga tetapi Gung Alit menggunakan ujaran dengan bahasa yang halus (basa singgih). Ini dibuktikan dari penggunaan kata "pengampura" yang 
termasuk ke dalam basa alus mider (Warna, dkk, 1990:20). Usia Gung Alit yang lebih muda dibandingkan Jero Sekar, Gung Ngurah dan kakek Giyor menyebabkan ia menggunakan bahasa yang halus saat melakukan ujaran, meskipun Gung Alit dari keturunan ksatria wangsa yang merupakan keturunan dengan kedudukan yang lebih tinggi dibandingkan dengan kakek Giyor dan Made Arini yang keturunan jaba wangsa. Made Arini yang memiliki usia yang lebih muda dan kedudukan yang lebih rendah tidak lantas menyebabkan Gung Alit menggunakan ujaran dengan basa sor, dikarenakan kesalahan yang dilakukan oleh Gung Alit memberikan kerugian yang besar kepada Made Arini.

Ujaran maaf yang dituturkan oleh Gung Alit dapat disimpulkan memiliki fungsi maaf agar penutur dibebaskan dari hukuman. Faktor yang memengaruhi penutur menggunakan ujaran "nunas pengampura" adalah hubungan yang akrab dimiliki oleh penutur dengan Jero Sekar, Gung Ngurah, kakek Giyor, dan Made Arini, perbedaan usia antara penutur dengan mitra tutur, status sosial penutur yang lebih tinggi dibandingkan kakek Giyor dan Made Arini, dan penutur dari anggota kelompok yang sama dengan Gung Ngurah dan Jero Sekar sebagai keluarga tetapi tidak dengan kakek Giyor dan Made Arini.

\subsubsection{Maaf untuk Menunjukkan Rasa Penyesalan}

Maaf untuk menunjukkan rasa penyesalan 7 buah ujaran. Berikut contoh hasil analisis untuk ujaran maaf menunjukkan rasa penyesalan.
(4) Ayu Adi
: Aji ampurayang titiang aji. Bas banget titiang ngrayanang aji sungkawa.

\begin{abstract}
Gusti Mangku : Ah, endapang suba Gég. Tegtegang ragan ceningé. Yén sube tuduhin Sang Hyang Widhi Wasa lakar nyabut uripé, mula tusing dadi kelidin
\end{abstract}

(Tresnané Lebur Ajur Satondén Kembang. 2011:17)

\begin{tabular}{|c|c|}
\hline Ayu Adi & $\begin{array}{l}\text { : Ayah maafkan saya } \\
\text { ayah. Saya terlalu } \\
\text { membuat ayah berduka. }\end{array}$ \\
\hline Gusti Mangku & $\begin{array}{l}\text { :Ah, biarkan sudah Gég, } \\
\text { kuatkan dulu dirimu. } \\
\text { Kalau Tuhan sudah } \\
\text { menghendaki kematian } \\
\text { kita, memang tidak } \\
\text { bisa dihindari. }\end{array}$ \\
\hline
\end{tabular}

Ujaran pada data (4) merupakan ujaran Ayu Adi dan ayahnya yaitu Gusti Mangku ketika Ayu Adi menangis dikarenakan kekasih dan teman-temannya meninggal. Ayu Adi yang belum dapat menerima kenyataan tersebut selalu menangis sepanjang hari dan menyebabkan ayahnya menjadi khawatir, sehingga Ayu Adi memohon maaf dengan ujaran "ampurayang" yang berarti "maafkan". Ujaran maaf Ayu Adi merupakan bentuk penyesalannya dikarenakan kesedihannya menyebabkan Gusti Mangku juga ikut bersedih. Mereka dari garis keturunan yang sama yaitu ksatria wangsa tidak menyebabkan Ayu Adi menggunakan basa sor. Ini dibuktikan dari digunakannya kata "ampurayang" yang merupakan kata yang masuk golongan basa alus mider (Warna, dkk,1990:20). Ayu Adi yang menggunakan ujaran dengan bahasa yang halus meskipun dengan keluarga. Selain itu, usia Gusti Mangku yang lebih tua menyebabkan Ayu Adi berbicara dengan menggunakan bahasa yang halus.

Berdasarkan ujaran maaf pada data (4), dapat disimpulkan memiliki fungsi 
maaf untuk menunjukkan rasa penyesalan penutur. Faktor yang memengaruhi penutur melakukan ujaran "ampurayang" yaitu faktor hubungan yang akrab sebagai anggota kelompok yang sama yaitu sebagai keluarga, usia penutur yang lebih muda dibandingkan mitra tutur dan status sosial yang sama sebagai keturunan ksatria wangsa.

\subsubsection{Maaf untuk Meminta Izin}

Maaf untuk meminta izin ditemukan 4 buah ujaran. Berikut contoh hasil analisis untuk ujaran maaf meminta izin.

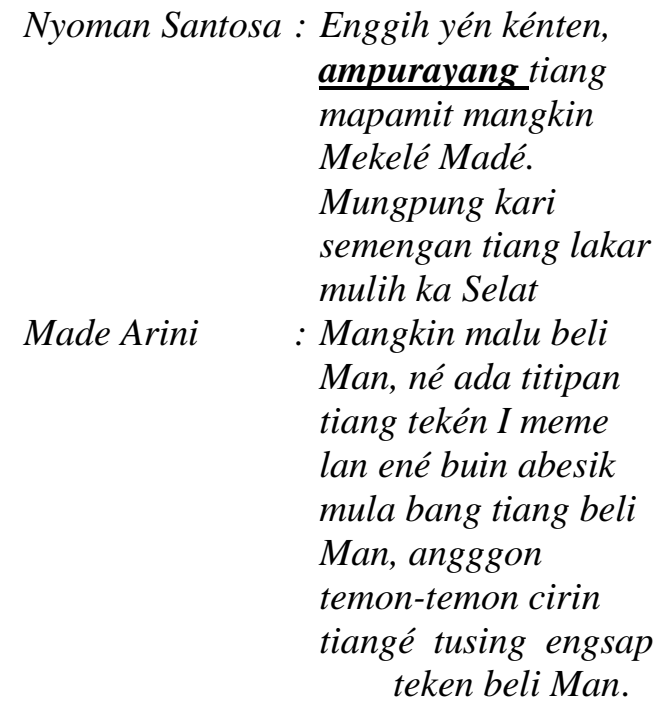

(Tresnané Lebur Ajur Satondén Kembang. 2011:147)

Nyoman Santosa : Iya kalau begitu, maafkan saya pamit sekarang Mekelé Made. Selagi masih pagi saya akan pulang ke Selat

Made Arini : : Tunggu dulu kakak Man, ini ada titipan saya untuk ibu dan ini lagi satu memang untuk kakak Man, untuk tanda mata menandakan saya tidak lupa kepada kakak Man.

Ujaran pada data (5) merupakan ujaran Nyoman Santosa dan Made Arini ketika Nyoman Santosa menginap di penginapan tempat Made Arini. Nyoman Santosa yang akan pamit pulang memohon maaf dengan ujaran "ampurayang" yang berarti "maafkan". Hubungan yang dekat antara Nyoman Santosa dan Made Arini dapat dilihat dari Made Arini yang memberikan tanda mata turun-temurun kepada Nyoman Santosa, meskipun mereka memiliki hubungan yang dekat, tetapi tidak menyebabkan mereka dapat menggunakan basa sor. Ujaran Nyoman Santosa yang mengatakan "...mekelé ..." merupakan penyebutan untuk wanita yang menikah dengan laki-laki bagsawan (Warna, dkk, 1990:440) menunjukkan akibat Made Arini yang telah menikah dengan seorang yang dari keturunan ksatria wangsa, menyebabkan status sosial mereka berbeda, sehingga Made Arini dan Nyoman Santosa menggunakan bahasa yang halus. Hal ini dibuktikan dari ujaran yang digunakan Nyoman Santosa yaitu "ampurayang" yang termasuk basa alus mider (Warna, dkk, 1990:20). Made Arini sebagai ksatria wangsa memiliki kedudukan yang lebih tinggi dibandingkan Nyoman Santosa yang hanya jaba wangsa meskipun usia Made Arini lebih muda dibandingkan dengan Nyoman Santosa.

Ujaran maaf yang dituturkan oleh Made Arini kepada Nyoman Santosa dapat disimpulkan, memiliki fungsi maaf untuk meminta izin. Faktor yang memengaruhi penutur menggunakan ujaran maaf "ampurayang" adalah faktor adanya kedekatan hubungan sebagau mantan kekasih, usia penutur yang lebih tua dibandingkan mitra tutur dan status sosial 
mitra tutur yang lebih tinggi dibandingkan penutur.

\subsubsection{Maaf untuk Merendahkan Diri}

Maaf untuk merendahkan diri ditemukan 1 buah ujaran. Berikut contoh hasil analisis untuk ujaran maaf merendahkan diri.

(6) Gusti Mangku: Gég... Ayu Adi, mai malu!

Ayu Adi : Inggih Aji, Aji, bibi, durusang wédangé.

Kéwanten ampurayang sanganane antuk ambon sida katur.

(Tresnané Lebur Ajur Satondén Kembang. 2011:9)

Gusti Mangku : Gég,,, Ayu Adi kesini dulu!

Ayu Adi : Iya ayah, Ayah, bibi, ini kopinya Tapi maafkan cemilannya sanggup memberikan abon saja.

Ujaran pada data (6) merupakan ujaran antara Ayu Adi dan Ayahnya yaitu Gusti Mangku ketika Ayu Adi sedang memberikan kopi dan abon untuk bibinya yang sedang berkunjung. Ayu Adi yang hanya memberikan kopi dan abon memohon maaf kepada Gusti Mangku dan bibinya. Ujaran maaf Ayu Adi yaitu "ampurayang" yang berarti "maafkan". Ayu Adi melakukan ujaran maaf dikarenakan Ayu Adi melakukan kesopanan dalam menjamu tamunya, agar Ayu Adi tidak terkesan sombong. Ujaran maaf yang dituturkan oleh Ayu Adi menunjukkan, meskipun mereka memiliki hubungan keluarga dan dari keturunan ksatria wangsa tidak lantas menyebabkan Ayu Adi menggunakan ujaran dengan basa sor. Ini dapat dilihat dari penggunaan kata "ampurayang" yang termasuk basa alus mider (Warna, dkk, 1990:20). Selain itu, usia Ayu Adi yang lebih muda dibandingkan Gusti Mangku dan bibinya menyebabkan Ayu Adi menggunakan bahasa yang sopan saat melakukan ujaran

Kesimpulan dari ujaran maaf pada data (6), menunjukkan bahwa ujaran "ampurayang" berfungsi maaf untuk merendahkan diri. Faktor yang memengaruhi penutur menggunakan ujaran maaf tersebut adalah faktor adanya kedekatan hubungan yaitu sebagai anggota kelompok yang sama yaitu sebagai keluarga, usia penutur lebih muda dibandingkan mitra tutur dan status sosial yang sama sebagai keturunan ksatria wangsa.

\section{Simpulan}

Hasil analisis menunjukkan bahwa dari tiga fungsi ujaran maaf yang ada menurut Alwi (2005) hanya terdapat dua fungsi maaf dalam bahasa Jepang yang terdapat pada novel Houkago ni Shisha wa Modoru karya Akiyoshi Rikako. Fungsi maaf pada novel bahasa Jepang yang berjudul Houkago ni Shisha wa Modoru terdapat dua belas buah ujaran maaf yang berfungsi menunjukkan rasa penyesalan dan enam buah ujaran maaf yang berfungsi meminta izin. Faktor yang sangat berpengaruh pada ujaran maaf dalam bahasa Jepang yaitu faktor kedekatan hubungan dan usia. Pada bahasa Jepang kedekatan hubungan dapat terlihat dari bentuk bahasa yang digunakan pada ujaran seperti bentuk biasa atau bentuk sopan. Pada ujaran maaf dalam bahasa Jepang yang terdapat dalam novel Houkago ni Shisha wa Modoru karya Akiyoshi Rikako ditemukan 15 jenis maaf yang digunakan yaitu gomen na, gomen ne, gomen, gomennasai, hontou ni gomen, hontou ni gomennasai, doumo sumimasen, kyuu ni sumimasen, yurushite, warukatta, waruikedo, warui, warui-warui, ojama shimashita, dan moushi wakenai. 
Ujaran maaf dalam bahasa Bali yang terdapat pada novel Tresnane Lebur Ajur Satonden Kembang karya Djelantik Santha, ditemukan empat fungsi maaf dari tiga fungsi yang dikemukakan oleh Alwi (2005) yaitu satu buah ujaran maaf yang berfungsi sebagai pembebasan dari hukuman, tujuh buah ujaran maaf yang berfungsi menunjukkan rasa penyesalan, empat buah ujaran maaf yang berfungsi meminta izin dan satu buah ujaran maaf yang berfungsi merendahkan diri. Pada ujaran permohoan maaf dalam bahasa Bali pengaruh status sosial dan usia sangat memengaruhi ujaran maaf dari penutur. Penanda kedekatan hubungan tidak dapat terlihat dengan jelas pada ujaran maaf dalam bahasa Bali, dikarenakan pengaruh sistem wangsa. Selain itu, pada ujaran maaf bahasa Bali yang terdapat dalam novel Tresnane Lebur Ajur Satonden Kembang karya Djelantik Santha, ditemukan enam jenis ujaran maaf, yaitu nunas pengampura, ampurayang, ngampurayang, ngidih pelih, ngidih kepelihan, dan matur sisip.

Hasil analisis menemukan dua buah persamaan ujaran maaf dalam bahasa Jepang dan bahasa Bali yaitu, Pada bahasa Jepang dan bahasa Bali, maaf tidak hanya digunakan ketika melakukan kesalahan, tetapi dapat juga digunakan untuk meminta izin seperti ketika akan pamit pulang dan Pada bahasa Jepang dan bahasa Bali terdapat berbagai jenis maaf yang digunakan sesuai norma yang berlaku dalam masyarakatnya.

Perbedaan ujaran maaf dalam bahasa Jepang dan bahasa Bali juga ditemukan yaitu 1) Pada bahasa Jepang hanya terdapat dua fungsi maaf tetapi pada bahasa Bali terdapat empat fungsi maaf; 2) Pada bahasa Jepang, kedekatan hubungan dan usia sangat berpengaruh pada ujaran penutur sedangkan pada bahasa Bali, status sosial yaitu sistem wangsa yang memiliki pengaruh besar pada ujaran yang digunakan penutur; 3) Pada bahasa Jepang kedekatan hubungan dapat dilihat dari ujaran yang digunakan, sedangkan pada bahasa Bali kedekatan hubungan tidak dapat dilihat dari ujarannya.

\section{Daftar Pustaka}

Alwasilah, A. Cheader. 2011. LINGUISTIK SUATU PENGANTAR. Bandung: Angkasa Bandung

Alwi, Hassan. 2005. KAMUS BESAR BAHASA INDONESIA .Jakarta: Balai Pustaka.

Djajasudarma, T. Fatimah. 1993. Metode Linguistik: Ancangan Metode Penelitian dan Kajian. Bandung: PT. Radika Aditama.

Levinson, Stephent C. 1983. Pragmatics. Cambridge: Cambridge Univercity Press.

Mahsun. 2013. Metode Penelitian Bahasa: Tahapan Strategi, Metode, dan Tekniknya Edisi Revisi. Jakarta: Raja Grafindo Persada.

Mizutani, Osamu dan Nobuko Mizutani. 1991. How to be Polite in Japanese. Tokyo: The Japan Times, LTD.

Rikako, Akiyoshi. 2014. 放課後に死者は戻 る. Tokyo: Futabasha

Sudaryanto .2015. METODE DAN ANEKA ANEKA TEKNIK ANALISIS BAHASA, 


\section{Pengantar Penelitian Wahana \\ Kebudayaan secara Linguistik.. \\ Yogyakarta: Sanata Dharma University Press.}

Santha, Djelantik. 2011. Tresnane Lebur Ajur Satonden Kembang. Tabanan: Pustaka Ekspresi.

Warna, I Wayan dkk. 1990. KAMUS BALIINDONESIA. Dinas Pendidikan Dasar Provinsi Dati 1 Bali. 